\title{
How teachers and teacher training are changing
}

\author{
Vittorio Midoro \\ Istituto Tecnologie Didattiche, CNR, via De Marini, 6, 16129 Genova, Italy. \\ midoro@itd.ge.cnr.it
}

Abstract: While the 20th century school focused on teaching, the 21st century school may well focus on learning. The role of teachers is changing to reflect this trend, and consequently teacher training processes are also changing. Teachers are becoming managers and facilitators of learning. To enhance children's learning, they design, adapt, manage and evaluate learning environments. These functions require competencies pertaining to three domains and their interrelationships: pedagogy, subject area and ICT. As far as the relationships among these domains are concerned, teachers should be aware of the changes brought about in the their subject area by the introduction of ICT. They should know how the didactics of their specific subject area are evolving and what new ways of learning are being opened up by ICT. To construct these new competencies, new teacher training processes, environments and policies are required. This paper describes a collaborative online learning environment for teacher training. It is shown how online education can be used to train teachers to create a learning community of European teachers. Researchers have developed "Medea", an online teacher training course in environmental education developed and run in the context of both a national programme and the European project "T3: Telematics for Teacher Training".

Keywords: Teacher training, online education, educational policies

\section{HOW TEACHERS' WORK IS CHANGING}

Information and Communication Technologies (ICT) are modifying our ways of communicating, sharing information, co-operating and learning. In the near future, teachers' competencies need to be enriched to embrace these changes. 


\subsection{The traditional pillars of teachers' competencies}

Knowledge of subject matter and basic pedagogy are the traditional pillars of teachers' competencies in modern day schooling. The importance of these two elements changes according to the school level. While pedagogic issues are crucial in primary school, those related to the subject matter assume greater importance for secondary school as the students' age increases. It is said that primary school teachers love their children, secondary school teachers love their curriculum area and university professors love themselves. Although the situation is changing, in some European countries aspiring primary teachers still commence studying a student teacher curriculum for secondary education (focusing mainly on pedagogical issues), while no specific pre-service training is provided for secondary school teachers, who merely require a degree in a given subject matter in order to teach it.

As to the subject matter, the problem is how to cope with the rapid growth of knowledge in specific curriculum areas and consequently deciding what teachers need to learn.

Regarding pedagogical issues, present-day schooling focuses more on teaching than learning. The transmissive paradigm not only affects approaches and methods, but also determines the layout of premises and classrooms. The higher the school level, the more the transmissive paradigm determines school structures. In this context, teachers should be capable of communicating, able to evaluate the impact of this communication on their students, and, more generally, have all those skills needed for effective transmission of their knowledge.

Within each subject area, a pedagogy has developed that relates specifically to that area, be it mathematics, foreign languages, history, etc. This fact can be thought of as the relationship between the subject matter and pedagogical knowledge applied to it.

Besides the subject and pedagogical knowledge, teachers' competencies involves skills that are hard to classify, such as the capacity to deal with conflict, to empathise with students and to operate in the school context (knowledge and practice of school laws and rules, active participation in school life, etc.).

\subsection{How children's learning is changing with ICT}

Computers and the Internet are changing the ways of learning adopted by children who use these tools. Working with the computer generally requires autonomy and independence. Novices continuously face problems when seeking to use the computer. Depending on their individual learning style, 
children either ask for help or try to solve problems by themselves. However, in the long run, frequent users acquire considerable autonomy, allowing them to solve most of their problems without any help. It is reasonable to assume that this independence applies not only to difficulties posed by computer use, but to cognitive problems in general. Moreover, the use of a computer application affects the ways in which related cognitive activities are performed. For example, a word processor changes writing styles. A browser or search engine affects the ways of searching for information. A graphic editor affects the ways of drawing. A database or spreadsheet influences the ways of organising data, a music editor those of composing music. Electronic mail and computer conferencing systems change ways of communicating using written language and so on. It is reasonable to assume that children, who use computers and the Internet, acquire new powerful learning skills through frequent interaction with virtual environments (computer games, editors, courseware, e-mailers etc). In this way, learning by doing and reflecting about one's own ways of operating become the main learning mode, in contrast with conventional schooling, where the main learning activities often consist of listening in classroom and performing pencil and paper tasks at home. Thus, the gap between school and children's lives widens, as does that between children who use computers and the Internet and those who do not have access to these resources.

\subsection{ICT: A new pillar in teachers' competencies}

As teachers cannot be excluded from the new ways of learning and new tools for improving individual productivity, communication and cooperation that have been brought about by computers and the Internet, their competencies should be improved to comprise a new fundamental pillar: skills pertaining to ICT. This competency will involve the ability to use the computer and web not only as individual productivity tools for writing, storing data, communicating, and sharing information, but also as tools for improving and facilitating their students' learning.

Computers and the Web are becoming ordinary tools for people who deal with information and knowledge. Thus they should also become thinking and working tools for teachers, to use both in class and in course management activities like writing reports, compiling statistics, communicating, collaborating with colleagues and parents, and so on. The systematic use of computers and the Internet will enrich teachers' competencies in directions not yet completely explored. Computer skills will soon become a prerequisite in any intellectual profession, and in particular for teachers, whose role it is to facilitate children's learning processes. 
Teachers' ICT competencies should involve aspects strictly connected with their role, covering both the curriculum area and the ways of learning. As far as the subject area is concerned, teachers should be aware of the changes being brought about by ICT. For example, using a word processor has changed the writing style of many professional writers. Computer simulation models have heavily affected "hard" sciences. Even in fields that are traditionally distant from hard sciences, such as music, painting etc, computers are used as a powerful tool for enquiry and expression.

But the aspect specifically related to teachers' work is the capacity to use computers to improve and facilitate children's learning within subject areas. This use entails changes in both content and methods. As to the former, numeric calculus in physics allows with the study of topics that were not previously dealt with since they required analytical calculus. In mathematics, evaluating the correctness of the results will acquire greater importance compared to calculus ability. In science, the ability to build computational models will become more important than recalling specific facts and figures. Historical databases will allow students to answer open questions and make hypotheses about connections between events.

The other aspect of the ICT-pedagogy coupling regards the ability to use applications for individual productivity and specific courseware in order to improve and facilitate personal reconstruction of knowledge. Teachers should know how to use the most effective courseware related to their subject, but should also know how to exploit fully the personal productivity tools suitable for their curriculum area.

\subsection{The teacher's new role}

Teachers' competencies will also involve the capacity to reflect on their own role and how it changes when the boundary conditions are modified. ICT develops children's autonomy and creates conditions for an independent reconstruction of knowledge by means of interaction with a social and biophysical environment. The teacher's task will increasing become one of adapting and developing learning environments to accommodate different learning styles. This task will be accomplished by reusing learning material available in different forms (print, off line and online, local or remote etc.) or producing new material, which can be shared with colleagues. Teachers' explanations will be replaced by rich audio-visual presentations available on CD-ROM or the Internet. Unsolved problems may be discussed with peers or eminent scientists. Students who are not able to perform an assigned task might ask peers for help or access a database of solutions. Formative tests could be automated to diagnose students' strengthens and weaknesses, along 
with possible reasons for failures and hints about what remedial material to use, and so on.

\section{ORIGINAL SOLUTIONS FOR IN-SERVICE TEACHER TRAINING}

Teachers' competencies will change to embrace knowledge and mastery of ICT, in such a way that they will become able to use and/or develop learning environments which both reflect how children learn outside school and facilitate the understanding of curriculum areas. This change is required now; we cannot stand by and wait for new generations of teachers to bring it about. But how can the retraining of several hundreds of thousand of teachers be achieved? Decision-makers have to tackle a crucial issue: how to promote quality learning processes in such a way that ICT skills become a basic pillar of the competencies possessed by all those in-service teachers. Solutions to this problem require a range of different strategies, the most promising of which seem to be those based on ICT and especially on online education (OLE) (Davis, 1998). The features of OLE allow the development of high quality learning processes for in-service teachers on a mass scale.

\subsection{Quality}

Like other forms of distance education, online education removes space and time constrains, but it also features a new characteristic which makes it more powerful than the others. In OLE, the availability of tools for rapid, reliable and cheap communication allows the implementation of forms of social and co-operative learning based on asynchronous written messages. As a result, not only are the time and space constrains typical of a classroom situation removed, but also the learning paradigm is changed. While the transmissive paradigm predominates in the classroom, in OLE the learning paradigm is social construction of knowledge, an approach far better suited to the needs of expert teachers. Here a community of experienced professionals uses the technology to share information, communicate, and co-operate, and learning takes place as a result of co-operative activity. In this process, new knowledge and material are created which become available for other teachers involved in future teacher-training processes. Three features characterise OLE:

1. a learning community, involving participants, tutors, experts, observers, etc;

2. a pool of resources; 
3. a telecommunications infrastructure with related services.

The community uses the telecommunications infrastructure and related services to communicate, access and share information, and co-operate. The material is available online on the Web or off-line. It may also be developed and sent out by tutors or other community members. A more detailed model of OLE is described by Midoro (1998). The strong points of this type of learning are its co-operative features and interaction among the participants. Moreover, written communication allows the storage and reconstruction of the co-operative process, providing the basis for evaluation and tuning of the whole learning process.

\section{$2.2 \quad$ Scale}

The ideal participant/tutor ratio is about thirty to one. A single course cannot be expected to meet the needs of a large number of trainees. However, the reusability of materials, methods and technology means that any online course can be repeated many times over, in series or parallel, provided that enough tutors are available. Moreover, courses are progressively enriched with each edition run, since they acquire new materials and management expertise. The apparent drawback of the OLE approach is the large number of tutors required to run courses in parallel sessions. But this problem can be overcome, considering that any run of the course "produces" people who are potentially capable of tutoring in an online course. Little effort is required to transform this potentiality into an effective availability of tutors, a point that will be discussed later in the paper.

Let us now see how these general statements have found practical application in a case of in-service teacher training.

\section{MEDEA: AN ONLINE TEACHER TRAINING PROGRAM}

At the outset in 1994, MEDEA was an online teacher training course regarding environmental education (EE). The idea behind MEDEA was to respond to the needs, constraints and structures of EE by adopting online education approaches (Briano, Midoro and Trentin, 1997). The course originated within the framework of LABNET, an R\&D project carried out by the Italian Research Council's Institute for Educational Technology (ITD) 
under the INFEA Programme, funded by the Italian Ministry for the Environment.

In MEDEA, a computer mediated communication system, First Class, was used to support learning activities that involved groups of teachers living in various Italian cities.

The course was based on a methodological approach proposed by ITD for the development and management of EE projects using educational technology. The chief objective was to give teachers the skills for designing and carrying out $\mathrm{EE}$ projects using this methodology. The approach comprises a number of phases (Midoro and Briano, 1996) and involves the planning and management of EE projects by groups of teachers from various disciplines. Rather than dealing with individual teachers, MEDEA addressed groups of teachers, the aim being to encourage local face-to-face interaction as much as possible. These groups met up at local EE centres or in their schools in order to use the necessary network links.

Ten groups of teachers located in various Italian cities were enrolled in MEDEA, and the course was led by three tutors, who were also experts in the specific subject matter. Five observers with an interest in the project also followed the course, without taking an active part in group work.

The course was organised into three main phases, each composed of a series of modules that ranged in length from 2 to 4 weeks (Table 1).

Table 1. MEDEA's schedule

\begin{tabular}{|lll|}
\hline \multicolumn{2}{|c|}{ Introduction } & \\
Module 0 & Course presentation and ice-breaking & 2 weeks \\
Module 1 & Educational Project & \\
Module 2 & Choice of environmental issue & 2 weeks \\
Module 3 & Definition of objectives & 2 weeks \\
Module 4 & Choice of specific environment & 2 weeks \\
Module 5 & Definition of a model for the specific environment & 3 weeks \\
Module 6 & Correlation with school curricula & 2 weeks \\
& Design of product to develop & 4 weeks \\
Module 7 & Design Phase & 1 week \\
\hline
\end{tabular}


Considerable emphasis was given to practical work and intercommunication in each module: phases of individual and group work alternated with periods of interaction with other groups and tutors/experts (methods and contents).

At the outset of the course, the students were given a kit of materials that included a user guide, articles, videotapes, publications, and so on. Each module was based on individual study of the material, discussion about the content, activities proposed by the tutor in each local group, communication of results obtained by the local groups to other groups, and inter-group discussion.

Upon completion of MEDEA, the groups were to produce a final product, namely their EE project. A final face-to-face meeting was held at the end of the course to discuss the whole experience. After this experience, MEDEA was re-tuned and run again in 1996.

In 1998, a Europe-wide edition of MEDEA, called EuMedea, (Briano et al., 1998) was run. The EuMedea project was born from the idea of creating synergy between the European project T3 (Telematics for Teacher Training) (Davis and Prosser, 1999), and the experience developed at national level with MEDEA. EuMedea involved practising and student teachers from five European countries: Finland, Italy, The Netherlands, Portugal and UK. Besides seeking to overcome some of shortcomings of MEDEA, the design of EuMedea entailed a number of adaptations to the multinational and multicultural context of T3 The course also needed to strike a balance between the different organisational requirements in the various countries. In this context an ad hoc methodology to validate online courses was developed and used (Bocconi et al., 1999).

In the following, we briefly describe the differences and similarities between MEDEA and EuMedea, pointing out the reasons for the changes introduced.

\subsection{Population}

While MEDEA was addressed to local groups of practising teachers, EuMedea's local groups were composed of teachers and/or student teachers co-ordinated by a local tutor. Online courses rely on the ability of participants to build new knowledge based on the experience of each member. In EuMedea we studied the effectiveness of this kind of learning with student teachers who had little or no classroom experience. To increase the efficiency of each group, we suggested they each appoint a local tutor, and we sought to widen group knowledge by giving them online access via $\mathrm{CMC}$ to an in-service teacher. 
Another important issue faced was language. We had been forced to choose a common language, English, which was the mother tongue of only one group. We studied how this influenced remote group communication and what could be done to minimise language-related problems. Finally, there was considerable variation in the contexts in which local groups operated. We studied the impact of this factor on the effectiveness of the course.

\subsection{Timing}

MEDEA lasted six mounts, while the EuMedea partners required a course duration of three months. As a consequence, we rearranged the content into three modules that covered the main points of the seven MEDEA modules.

\subsection{Technology}

Both MEDEA and EuMedea used a computer mediated communication system. However, since EuMedea took place in the context of a European project dealing with telematics, visibility through the web was an important requirement. On the other hand, course participation had to be limited to registered participants. These dual requirements meant that while there was a need for all Internet users to access EuMedea so as to observe it, an Intranet approach was called for to restrict communication to a given community. We chose to support EuMedea using the most recent release of FirstClass, because it allowed us to implement a system offering both possibilities.

Online courses usually start and end with face-to-face meetings, where participants familiarise with each other. In our experience these events are very useful for creating a friendly environment for course interaction. In the context of EuMedea, face-to-face meetings would have been too expensive so as an alternative we planned an initial and a final multi-point videoconference.

In 1999, MEDEA became an annual training program involving a set of parallel courses based on a revised version of the original.

Here, the key idea was to test two hypotheses:

1. tutors, other than the original course designers, are able to hold the MEDEA course;

2. a percentage of MEDEA alumni can become MEDEA tutors. 
Confirmation would have meant that we had found a possible key to solving the problem of the great number of teachers to be trained. Three teams of tutors planned, organised and held three MEDEA courses in three different environmental education labs, (in Milan, Udine and Genoa) with excellent results. MEDEA99 verified the first hypothesis. However, it became clear that to ensure the "portability" of the course, some tools for future tutors had to be developed.

Late 1999 began MEDEA2000, which involves five courses, with 78 groups and 335 participants. MEDEA2000 tutors are both tutors and alumni of MEDEA99. The MEDEA2000 program started with a short two-day introductory course for the nine tutors. A tutor guide was developed to facilitate the tutors' work, and a conference area was opened to provide them with on-going assistance. The tutors were given tools for " real time" course validation, helping them to monitor the effectiveness of the course at any moment. MEDEA2000 is still in progress, but initial results have confirmed the second hypothesis.

\section{LESSONS LEARNT}

MEDEA shows how ICT can be used to develop quality mass teachertraining courses that deal with both an interdisciplinary content (EE in this case) and educational technology applied to that content. Below, some of the lessons learnt are briefly described.

1. MEDEA shows that it is possible to develop online courses that are effective and reusable for in-service teacher training. The MEDEA approach can be generalised to the development of online courses dealing with various curriculum areas, whose design involves both OLE and content experts. This should ensure the quality of these courses.

2. EuMedea has shown that adapting a well-designed online course to very different contexts is easy to accomplish and cheap as far as human and financial resources are concerned. Far from posing an obstacle, the differences arising in the different contexts may actually prove to be a source of wealth.

3. MEDEA99 has shown that tutors not involved in the development of an online course can run it successfully, with no significant lost of quality.

4. MEDEA99 has shown that instructional and support tools are useful for assisting new tutors to run courses designed by others.

5. In MEDEA2000 these tools consisted of a two-day course, a tutor guide and a conference area in the CMC system for posing questions and asking for help from more experienced tutors. These tools were effective in MEDEA2000 and may also prove effective for other kinds of online 
courses. In any case, tools for helping tutors should be designed to ensure course portability.

6. Environmental education labs supported both MEDEA99 and MEDEA2000. These belong to a national network of EE labs called LABNET. ITD provided the CMC system and assisted the novice tutors while they were running the course. The lesson learnt is that in order to disseminate an online course, structures are required that can accomplish the tasks that in MEDEA were performed by the EE labs and ITD.

7. The described dissemination mechanism involves two apparently contrasting elements: a centralised element covering overall system planning matters, such as management of the whole program, administration of the CMC system, tutor assistance facilities etc.; and a local element entailing tasks like recruiting participants, localising the course, organising the local initial and final meetings, etc. The MEDEA experience has shown that this combination of centralism and localism can be very effective, provided that the quality of the whole system is continuously monitored.

\section{CONCLUSIONS}

The diffusion of computers and the Internet is comparable to that of telephone and television in the recent past. The scenario whereby every family has got one or more computers and Internet access is fast becoming a realistic one. These tools profoundly modify not only the ways of communicating, but also the ways of learning, co-operating and working. Schooling should change to accommodate this new situation and, in the process, the teacher's role should change. Teachers' competencies ought to be enriched to comprise ICT skills for both personal productivity and for use as a tool to facilitate children's learning. We cannot merely wait for a new generation of teachers to bring this change about; a great number of inservice teachers need to be retrained.

This paper has sought to help find possible solutions to the problem of how to train hundreds of thousands of in-service teachers. ICT and the outcomes of recent research in education technology can help us tackle this issue. MEDEA, an annual program of online courses that each year involves an every great number of participants, is an example of how ICT can be used for that purpose. Some of the lessons learnt have been discussed, but the main suggestion is that the solution to the problem of quality mass in-service teacher training can be found by connecting ICT, research and local educational structures, co-ordinated by means of central programs and structures. 


\section{REFERENCES}

Bocconi, S., Midoro, V., and Sarti, L. (1999) Valutazione della qualità nella formazione a distanza, Tecnologie Didattiche, 1, 24-40.

Briano, R., Midoro, V., and Trentin, G. (1997) Computer mediated communication and online teacher training in environmental education, Journal of Information Technology for Teacher Education, 6, 127-145.

Briano, R., Midoro, V., Persico, D., Sarti, L., and Trentin, G. (1998) EuMedea, a European online course to train European teachers in Environmental Education, Proceedings of the XV IFIP World Computer Congress "Teleteaching '98", 31 August - 4 September, Vienna/Budapest.

Davis, N. (1998) Developing telecommunications within European teacher education: progress, plans and policy, Proceedings of the SITE (Society for Information Technology and Teacher Education) 98 International Conference, Washington, DC.

Davis, N. and Prosser, D. (1999) T3 final report, [http://telematics.ex.ac.uk/t3/deliver.htm].

Midoro, V. and Briano, R. (1996) Learning by doing: Teachers and students working cooperatively to create hypermedia, Proceedings of ED-MEDIA 96, Boston, 483-489.

Midoro, V. (1998) Modelling online education, Proceedings of ComnEd 99, Aulanko, Finland, 239-246.

\section{BIOGRAPHY}

Vittorio Midoro received his doctoral degree in 1972 . He has been working in educational technology since 1974 and has been responsible for many research projects dealing with both methodological issues and theoretical issues. At present he is project manager of LABNET, a project funded by the Italian Ministry of Environment, aimed a developing a network of environmental education labs. His present activity involves online education, co-operative learning, and the use of telematics in environmental education. 